$1-19-2021$

\title{
A Watched Pot Never Boils: Attentive Care Needs No Timer
}

Dennis J. Baumgardner

Follow this and additional works at: https://aah.org/jpcrr

Part of the Family Medicine Commons, Family Practice Nursing Commons, Health and Medical Administration Commons, Health Services Research Commons, Internal Medicine Commons, Medical Education Commons, and the Primary Care Commons

\section{Recommended Citation}

Baumgardner DJ. A watched pot never boils: attentive care needs no timer. J Patient Cent Res Rev. 2021;8:5-7. doi: 10.17294/2330-0698.1827

Published quarterly by Midwest-based health system Advocate Aurora Health and indexed in PubMed Central, the Journal of Patient-Centered Research and Reviews (JPCRR) is an open access, peer-reviewed medical journal focused on disseminating scholarly works devoted to improving patient-centered care practices, health outcomes, and the patient experience. 


\title{
A Watched Pot Never Boils: Attentive Care Needs No Timer
}

\author{
Dennis J. Baumgardner, MD | Editor-in-Chief \\ Department of Family Medicine, Aurora UW Medical Group, Advocate Aurora Health, Milwaukee, WI
}

$\mathrm{W}$ ithin this issue of the Journal of PatientCentered Research and Reviews (JPCRR), a brief report authored by Leung and colleagues describes a cross-sectional survey of inpatients and their treating physicians in regard to length of clinic visits. This study found no association between physician burnout and the amount of time patients perceived the physician spent with them at the bedside. ${ }^{1}$ For me, a primary care physician who has certainly experienced time pressures when seeing inpatients and outpatients, ${ }^{2,3}$ the key word here is "perceived."

Internationally, the length of primary care consultations varies considerably, with an estimated half of such visits worldwide lasting less than 5 minutes. ${ }^{4}$ Average consultation times in the United States and United Kingdom are at least twice that long, with the former exceeding 20 minutes. ${ }^{4}$ Differences in typical length of clinic visits also have been reported within each country; yet, ultimately, patient satisfaction was not associated with this factor. ${ }^{5}$ Nonetheless, a 2015 study found that more than one-third of U.S., U.K., and other Westernworld primary care physicians expressed concern about lack of time with patients. ${ }^{6}$ Other reports, including new research into patient perceptions of weight stigma by providers published within this issue of JPCRR, have proposed longer consultations or patient-centered medical homes as means to improve primary care. ${ }^{7,8}$ The doctor's mantra seems to translate to "give us more time and we'll give you better results;" while for patients, "if you make it good, it can be quick" carries the day.

According to Lussier and Richard, patients perceive that clinicians have limited time for consultations through contextual clues (busy waiting rooms and staff, fastpaced office), which may skew their recollection as to how long their actual consultation lasted. ${ }^{9}$ A paradox is that while short consultations are a major source of patient dissatisfaction in primary care (along with other process-related issues such as ease of obtaining urgent

Corresponding author: Dennis J. Baumgardner, MD, Aurora Sinai Medical Center, 1020 N. 12th Street, \#4180, Milwaukee, WI 53233 (dennis.baumgardner@aah.org) appointments and length of time spent in waiting room), lengthening the time spent with the patient has demonstrated little impact on patient satisfaction. ${ }^{9-11}$ Based on 440 video-recorded patient consultations with willing general practitioners, Elmore and colleagues found no association between length of consultation and any of 3

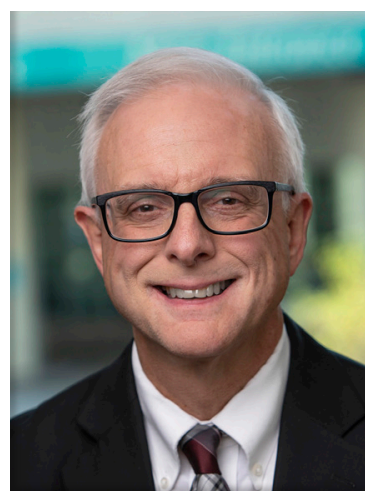
measures of patient experience, including satisfaction. ${ }^{12}$ Similarly, in a study of 160 timed adult patient encounters with 9 general practitioners in the United Kingdom, patient satisfaction obtained following the encounter did not correlate with actual consultation duration but was associated with the patient's perceived length of the consultation. ${ }^{13}$ Finally, Lin et al studied 1486 consecutive ambulatory visits to an academic community internal medicine clinic in Denver, Colorado. ${ }^{3}$ Patients were queried pre- and postvisit regarding time expectations and perceptions of actual time spent, and physicians completed a postvisit questionnaire regarding their perception of time spent and patient satisfaction with the visit. ${ }^{3}$ Patient and physician length of visit estimates offered after the visit both exceeded patients' previsit expectations. Of note, patient satisfaction correlated with whether actual time estimates were longer or shorter than previsit expectations. ${ }^{3}$ This indicates that it may be more productive to determine each patient's anticipated length of clinic visit as opposed to striving to extend the time allotted for all visits.

Or, perhaps the more relevant goal should be to improve the patient-physician interactions that transpire over any time frame?

Ogden and colleagues surveyed 294 patients following a general practitioner consultation in the United Kingdom. ${ }^{14}$ The practitioner recorded the consultation time and asked each patient to estimate the length of the visit while in the exam room; surveys were otherwise completed in private, including a question regarding the patient's preferred length of consultation. The preferred and actual time of consultation were similar (almost 9 minutes), 
while the patient-estimated time was a bit less (just over 8 minutes).${ }^{14}$ Controlling for real and perceived time, the authors found that subject desire for more consultation time correlated with emotional needs not being met during the visit (which also lessened the likelihood of patients following physician recommendations). ${ }^{14}$ They postulated that their results ${ }^{14}$ supported sociologist David Mechanic's original concept of "meaningful time" eg, addressing primary patient concerns, partnering on care plans, and trust-building - being most valued by patients. ${ }^{15}$ In addition to effects on patient satisfaction, actual shorter consultation time as well as the perception of insufficient time are associated with increased patientreported unexpected or adverse reactions to treatment. ${ }^{16}$

A systematic review of European and Australian publications on general practitioner consultation length and patient satisfaction (which included the results from Ogden et $\mathrm{al}^{14}$ ) suggested that the length of consultation, per se, is not predictive of patient satisfaction. ${ }^{17}$ Rather, satisfaction is increased if the consultation is long enough to explore the patient's psychosocial factors or needs. ${ }^{17}$ A study of 112 consecutive patient visits to a hand surgeon indicated that patient satisfaction did not correlate with consultation duration or previsit duration expectations, but rather with perceptions of surgeon empathy (depression symptoms were another correlate). ${ }^{18}$ Similarly, the study by Elmore et al revealed no association between visit duration and a patients' trust or confidence in their general practitioner. ${ }^{12}$ Regarding the aforementioned feedback from women of higher weight reported by Watson and colleagues, which included a desire for longer consultations, ${ }^{7}$ I offer the possibility that had these patients not felt so stigmatized by their health care interactions in the first place, they may have perceived the time regularly allotted to visits as sufficient.

In the eyes of patients, time is what we make of it. To that end, Torres and colleagues recommend that consultation time be "humanized," such that the targeted duration of a clinic visit respects the needs of the patient and the time and obligations of both patient and clinician. ${ }^{2}$ However, frequently the optimum visit length cannot be precisely estimated based on stated concerns at the time of scheduling. Besides being unrealistic, trying to achieve such finely tuned customization of time misses the point.

Rather, when it comes to patient consultations, if television producer Jonathan Estrin is correct in saying that "the way we spend our time defines who we are," then perhaps the perceived duration of consultation is less important than - to borrow from the much more renowned Dr. Martin Luther King - the perceived "content of our character."

\section{Acknowledgments}

The author thanks Joe Grundle, managing editor of $J P C R R$, for his helpful suggestions regarding this and all From the Editor articles.

\section{References}

1. Leung SJ, Panda M, McIntosh G, et al. Relationship between physician burnout and patient's perception of bedside time spent by physicians. J Patient Cent Res Rev. 2021;8:58-63.

2. Rodríguez Torres AR, Jarillo Soto EC, Casas Patiño D. La consulta médica, su tiempo y duración. [Medical consultation, time and duration.] Medwave. 2018;18(5):e7264. CrossRef

3. Lin CT, Albertson GA, Schilling LM, et al. Is patients' perception of time spent with the physician a determinant of ambulatory patient satisfaction? Arch Int Med. 2001;161:1437-42. CrossRef

4. Irving G, Neves AL, Dambha-Miller H, et al. International variations in primary care physician consultation time: a systematic review of 67 countries. BMJ Open. 2017;7(10):e017902. CrossRef

5. Alarcon-Ruiz CA, Heredia P, Taype-Rondan A. Association of waiting and consultation time with patient satisfaction: secondary data analysis of a national survey in Peruvian ambulatory care facilities. BMC Health Serv Res. 2019;19:439. CrossRef

6. Osborn R, Moulds D, Schneider EC, Doty MM, Squires D, Sarnak DO. Primary care physicians in ten countries report challenges caring for patients with complex health needs. Health Aff (Millwood). 2015;34:2104-12. CrossRef

7. Watson D, Hughes K, Robinson E, Billette J, Bombak AE. Patient recommendations for providers to avoid stigmatizing weight in rural-based women with low income. J Patient Cent Res Rev. 2021;8:20-30.

8. Fiscella K, Epstein RM. So much to do, so little time: care for the socially disadvantaged and the 15-minute visit. Arch Intern Med. 2008;168:1843-52. CrossRef

9. Lussier MT, Richard C. Time flies: patients' perceptions of consultation length and actual duration. Can Fam Physician. 2007;53:46-7.

10. Sans-Corrales M, Pujol-Ribera E, Gené-Badia J, Pasarín-Rua MI, Iglesias-Pérez B, Casajuana-Brunet J. Family medicine attributes related to satisfaction, health and costs. Fam Pract. 2006;23:308-16. CrossRef

11. Wilson A, Childs S. The effect of interventions to alter the consultation length of family physicians: a systematic review. Br J Gen Pract. 2006;56:876-82.

12. Elmore N, Burt J, Abel G, et al. Investigating the relationship between consultation length and patient experience: a crosssectional study in primary care. Br J Gen Pract. 2016;66:e896903. CrossRef

13. Cape J. Consultation length, patient-estimated consultation length, and satisfaction with the consultation. Br J Gen Pract. 2002;52:1004-6.

14. Ogden J, Bavalia K, Bull M, et al. "I want more time with my doctor": a quantitative study of time and the consultation. Fam Pract. 2004;21:479-83. CrossRef

15. Mechanic D. How should hamsters run? Some observations about sufficient patient time in primary care. BMJ. 2001;323:266-8. CrossRef

16. Mira JJ, Nebot C, Lorenzo S, Pérez-Jover V. Patient report on information given, consultation time and safety in primary care. Qual Saf Health Care. 2010;19:e33. CrossRef 
17. Lemon TI, Smith RH. Consultation content not consultation length improves patient satisfaction. J Fam Med Prim Care. 2014;3:333-9. CrossRef
18. Parrish RC 2nd, Menendez ME, Mudgal CS, Jupiter JB, Chen NC, Ring D. Patient satisfaction and its relation to received visit duration with a hand surgeon. J Hand Surg Am. 2016;41:257-62. CrossRef

(C) 2021 Advocate Aurora Health, Inc. 